\title{
Maintenance Culture Management for Global Impact
}

\author{
Miebi Ugwuzor* Tarela Oboro Okpu Margaret Diete-Spiff \\ Department of Management,Niger Delta University, Wilberforce Island, P.M.B. 071, Yenagoa,Bayelsa State,
} Nigeria

\begin{abstract}
Noble and concerted efforts have been made in many respects in the development of Africa. Although a lot seems to have been achieved, a lot more is still left to be desired in order to attain the optimum level of development and boost the contributions of African States, particularly those in the Sub-Saharan region, in key areas of positive global best practices. The need for the consciousness of maintenance culture cannot be over stressed if the continent is to attain her full potentials. Maintenance culture Management could act as a key driver in sustaining competitive advantage in as well as ensuring sustainability of processes in social and organizational settings. Thus, this is one critical area of immense potential developmental benefit to the continent and a veritable avenue to impact the global space. Through participative observation and desk research, this exploratory paper took an introspective look at the macro, micro and mini level perspectives of Maintenance culture Management. This was done to trigger behavioral alterations in the different dimensional perspectives and within the African continental environment with a view to changing the current unfavorable narrative and increasing her potentials for better global impact.
\end{abstract}

Keywords: Africa, culture, development, global, maintenance, management.

DOI: $10.7176 / \mathrm{JRDM} / 64-04$

Publication date: April $30^{\text {th }} 2020$

\section{INTRODUCTION}

Africa is a Continent greatly endowed with resources of various dimensions with a lot of potentials for growth and development. She also possesses ample potentials to be a key driver of the world economy. The 2020 Economic Outlook of the Continent from the African Development Bank shows general continuous improvement in her economic performance with a stabilized economic growth of 3.4 percent in 2019 and is projected to pick up to 3.9 percent in 2020 and accelerate to 4.1 percent in 2021 (African Development Bank,2020) . This optimistic outlook of the Continent gives an apparent sense of accomplishment to member States. Although some African States may enjoy more developmental outlook than others, in the spirit of Pan Africanism, no State should be allowed to lag behind in any area of development. Glaring indicators of gross under development still stare some African States in their faces.There are still issues of low income, comatose public utilities poverty, inadequate health care, other basic infrastructure as well as overall insecurity, backwardness and high level of unemployment(Mwenzwa\&Misati,2014:Ojo,2016).

Apart from the aforementioned, the industries tend to lack adequately trained personnel to man equipment, machinery and technology, among other inadequacies required to boost the various productive sectors. Nigeria, for example, has witnessed grand schemes and great projects set up to improve the welfare and wellbeing of its people as well as for the growth of the country economically. Policies with good intentions like the Structural Adjustment Programme (SAP) and other numerous welfare programmes as well as the massive but comatose, moribund and crumbling refineries, the Nigerian Airways, to mention but a few have gone under apparently due to the lack of maintenance culture management. Maintenance as a strategic decision can remove any potential of equipment failure, deterioration, stoppages and breakdowns (Mad Lazim \& Ramayah, 2010).Maintenance strategies have been seen in various dimensions. Patidar, Soni,\& Soni, (2017) observed that maintenance strategies could be planned maintenance, unplanned maintenance, breakdown maintenance, preventive maintenance, predictive maintenance, pro-active maintenance and synergic maintenance. To Mungani \&Visser (2013) a number of different maintenance approaches, which are sometimes referred to as strategies or philosophies, are available for application. They include Reliability-Centred Maintenance (RCM), Total Productive Maintenance (TPM) and Business-Centred Maintenance (BCM). Maintenance culture suggests the habit of regularly and consistently keeping buildings, machines, facilities, equipment, infrastructures and so on, in good working condition (Tijani,Adeyemi,\& Omotehinshe,2016). Going by the current observable lax attitude to equipment, facility and process maintenance management in private and public concerns, chances are that the various industrial sectors are not likely to receive the appropriate boost. Thus, there is a need for a strategic and radical intervention. This paper discussed maintenance culture management as it relates to the handling of physical assets and organizational processes as against Beheshtifar \& Safarian (2013) view of the maintenance function of Human Resource Management which covers employee wage, welfare and safety plans in workplace as well as preventive actions, medical care actions, welfare services, retirement actions, and insurance actions. 


\section{THEORETICAL UNDERPINNING}

The theoretical underpinning of this work hinges on the Social Development Theory (Vygotsky, 1978). The work of Vygotsky(1978) attempts to explain qualitative changes in the structure and framework of society which help the society to better realize aims and objectives. Development is a process of social change and could be seen as an upward ascending movement featuring greater levels of energy, efficiency, quality, productivity, complexity, comprehension, creativity, mastery, enjoyment and accomplishment (Jacobs \& Asokan, 1999). The theory explains that socialization affects the learning process in an individual and believes that consciousness or awareness is as a result of socialization. The Social Development Theory emphasizes the effect of culture and social factors in contributing to cognitive development. Huitt, \& Dawson (2018) believe that the home environment has a powerful influence on social development. Looking at the traditional African society, one could observe the closely knit social structure. People socialize and learn from others. If each person tells the other, be it, at the mini, micro and macro levels, irrespective of the starting point of learning, then everyone will likely be informed on the management of maintenance culture and how this can better the society.

This work also took a fundamental background in Terotechnology. File (1993) defined Terotechnology as a combination of management, finance, engineering, building, and other practices applied to physical assets in pursuit of economic life costs. In practice, it is concerned with the specification and design for reliability and maintainability of plant, machinery, equipment, buildings, and structures. It is also concerned with installation, commissioning, maintenance, modification, and replacement. Terotechnology will not be complete without feedback of information on design, performance, and costs. Maintainability, to Juran \& Godfrey (1999), is the ability of an item under stated conditions to be retained in or restored to, within a given period of time, a specified state in which it can perform its required functions when maintenance is performed under stated conditions and while using prescribed procedures and resources. Obsolescence and availability of spare parts seem not to be considered during procurement as some equipment and machinery brought into some African countries are only discovered to be easier replaced than maintained thus wasting funds that could have been used to procure cheaper alternatives in the first place. Maintenance culture management is geared towards looking at these factors and all other ancillary factors which seem to cause wastages and hinder smooth operations at the macro, micro and mini levels.

\section{MAINTENANCE CULTURE MANAGEMENT}

Maintenance culture management is the state of bringing the culture of maintenance deep into the consciousness of individuals, families, small groups, private firms and the government to the extent that everyone practices and advocates strict adherence to maintenance practices in whatever domain they occupy. Suwaibatul Islamiah , Abdul Hakim ,Mohd \&Mariah(2012) defined Maintenance culture as the values, ways of thinking, behavior, perception and the underlying assumptions of any person or group or society that considers maintenance as a matter that is important and practices it in their life.

Maintenance culture management goes beyond keeping equipment, tools, facilities, buildings and work processes in good and stable working conditions but also ensures that there is a consciousness to strive for continuous improvement by placing structures which check for obsolescence in order to adapt to innovations and a new status quo. Thus, if maintenance culture is properly managed, there will be a constant conscientized reminder of the relationship between maintenance practices and the greater good of all in the immediate environment and beyond.

In this work, Maintenance Culture Management was looked at in three dimensions. They include the Macro level Maintenance Culture Management, which is concerned with imbibing a maintenance culture consciousness at the public (government) level, the Micro level Maintenance Culture Management, which is concerned with acquiring a maintenance culture consciousness at the Private (Firm and small group) level and the Mini level Maintenance Culture Management, which is concerned with learning a maintenance culture consciousness at the individual and family unit level.

\section{Macro Level Maintenance Culture Management}

Macro Level Maintenance Culture Management focuses on putting the consciousness of maintenance culture deep in managers of public utilities and government owned facilities, infrastructure, operations and processes. During primitive times, Africans were known to have fashioned tools for farming, fishing, communicating and for other productive efforts. These tools were maintained so much that they were always in good working conditions. The administrative processes and operations at that time were said to be highly organized and coordinated with little or no bottle necks. Historical accounts of traditional African systems that worked very well abound and are concisely documented (Asimeng-Boahene, 2017; Fonchingong, 2018; Kangalawe, Noe, Tungaraza, Naimani, \& Mlele, 2014; Kisangani, 2009).

With the advent of modernization one would expect that the traditional maintenance cultural practices will be taken to more sophisticated levels but apparently this is not the case. This may be observable in the level of 
dilapidation, damage and decay in many public utilities and government owned facilities, infrastructure, operations and processes in many African States (Amankwah, Wai, Mohammed,.\& Baba,2017;Magutu \& Kamweru,2015)

Despite huge Government spending on the procurement of the best equipment and machinery for their various establishments, they are made to rot away. Tijani, et al. (2016) believe that to achieve sustainable development goals, there is need to have a national policy on maintenance in all tiers of government, such that maintenance culture should be a course for all levels of the educational curricula as well as a great need to have facility managers who rose to the ranks of leadership on the basis of merit who will ensure that facilities and infrastructures are continuously improved on.. It is worth mentioning that Nigeria and many African States have approved National Infrastructure Maintenance Frameworks. If one should ask about the maintenance policies of refineries, steel plants, transportation systems (roads, airport, railways, water ways, motor vehicles,) telecommunications, power and water boards, among others, a catalogue of maintenance policies and strategies will be presented. Although many government and agencies have policy documents on regular maintenance practices, the actual reports on the on-the-spot- assessment are not very palatable. Suffice it to say that the lack of the implementation of these frameworks or policies in line with the tenets of maintenance culture management has led to the loss of huge sums of money and even lives due to premature replacement, avoidable accidents, incessant disruption of utilities and other critical ancillary facilities all of which have led to the continuous underdevelopment of States in the Continent and brought untold hardship to the ordinary citizens. There is an urgent need for maintenance culture consciousness at this level because of its strategic importance to the development of States in the Continent and the implication of this in the global environment.

\section{Micro Level Maintenance Culture Management}

This level addresses the issues of the maintenance culture consciousness of firms and small groups in the society. There are sad and unfortunate experiences where huge investments are lost due to poor maintenance culture of firms. Poku and Lamptey (2014) opined that the failure of business enterprises in terms of their facilities and equipment can cause serious social and economic consequences for their operations. Apart from the industry acceptable standards and government regulations and policies, firms should take routine practices of maintenance as part of the organizations culture noting that the maintenance practices of firms differ depending on the industry. By so doing, they will reap ample benefits for themselves. Practicing managers of firms could also take the initiative to take the management of maintenance culture as an advocacy social responsibility stance to create awareness to their staff and individual in their homes and immediate environment. Usman, Gambo and Chen (2012) advice African leaders to allocate more resources for maintenance purposes and ensure strict compliance for the usage and educate the masses on the importance of having a proactive maintenance culture. The consciousness of maintenance culture could help firms improve efficiency, boost output and attract investors. If each one tells one, then the multiple multiplier effect will maximize the inherent benefits to one and all.

\section{Mini Level Maintenance Culture Management}

Maintenance culture consciousness of individuals, families and households is the focus at this level. This level looks at learning maintenance culture from the personal level and to improve the wellbeing of families and small households. Bandara, Dehejia \&Lavie-Rouse (2017)found a systematic evidence of a relationship where by household resources enhances human development and human development also increasing resources. The maintenance of personal health and wellbeing is also important at this level. Apart from lack of regular medical checks and self- medication which are rampant in many societies, there are still cases of neglect of leaking roofs and other building defects in privately owned buildings as well as unhygienic environmental practices .The slogan of a "stitch in time saves nine" should be the watch word at this level so that if an individual notices as little as a tear on a mundane item as a personal or household fabric the person's consciousness is steered to stitching it immediately. Maintenance culture consciousness can start and end at any level. However, going by the axiom that "charity begins at home", one could surmise that if there is proper maintenance culture management at this level, the individuals and their households will take it as normal family practice. The individuals will likely be groomed in such a way that personal and household tools, machines and equipment will always be in good working condition while wastages and regular replacement will be reduced. Besides, the individuals who manage private and government-owned establishments come from families and a good mini level maintenance culture consciousness may positively translate to how they manage their establishments.

\section{POTENTIAL HINDRANCES TO MAINTENANCE CULTURE MANAGEMENT.}

Suwaibatul Islamiah, et al. (2012) believe that leadership, communication, rewards and recognition, teamwork, among other factors could facilitate the development of a maintenance culture. Indeed many individuals, firms and governments may be genuinely desirous of imbibing and adhering to best practices in the management of 
maintenance culture at the different levels. However, to positively alter the current narrative, the following identified hindering factors will need to be addressed.

1. Ignorance: Many actors at the mini, micro and macro levels seem ignorant of the implications of the detrimental effects of improper maintenance culture management. They tend to lack the requisite consciousness on the maintenance of certain assets and processes and may not also comply with maintenance instructions. The key actors go about their activities unperturbed in the face of glaring looming danger. Even when there is an attempt at maintenance culture management, the rule of thumb is practiced and wrong maintenance practices are carried out .The lack of expertise and proficiency exhibited tend to escalate the danger levels. There is a need for education ,enlightenment as well as orientation and reorientation of all and sundry on maintenance culture consciousness. Practices ranging from repairing, recovering to recycling items can serve as little beginnings to instilling a maintenance culture in members of the society at all levels.

2. Inadequate budgetary allocation: No doubt money, time and energy will have to be spent on maintenance .Economic constraints may be a reason for inadequate budgetary allocation for maintenance .However, in a situation when it is thought that budgetary allocation for maintenance is a waste, when disaster strikes due to poor maintenance culture management there will be no good enough reason to equate any irreparable loss or damage. Substantial and tangible budgetary allocation by relevant stakeholders should be made at the mini, micro and macro levels for the maintenance of processes, facilities and equipment as the case may be.

3. Corruption: In the countries where there is high level corruption, it is assumed that people will only be committed to the progress of something if they can get something from it. Government property is regarded as nobody's property so that anything can happen to it. Government officials fail to maintain equipment and leave it to deteriorate so that the contract sum for replacement could be high enough to receive a high "kick-back". There is also a scenario where facilities and infrastructure could be left unmaintained for a long time owing to minor faults so that they could be regarded as scrap to be bought at a cheaper cost by the managers and personnel in such corrupt settings. To combat this, the awareness of the importance of maintenance culture consciousness should be intensified together with a strong anti-corruption campaign.

\section{GLOBAL IMPACT}

Africa has the second highest population of the world. As of 2019, it was estimated that approximately 1.3 billion people were living in 54 different countries in the Continent (Worldometer, 2020). With her huge active population and other distinctive competences the Continent has very bright prospects of carving a unique niche in world affairs. A society cannot be said to be developed if dilapidated physical structures and substandard products and services are predominant. The global demand for goods and services from Africa will not reach the optimum level if the present negative narrative does not change. Africa is a continent made up very hard working and industrious people with very high capacity to learn new skills and competences all of which could be leveraged upon to impact the global environment. Poor management of maintenance culture has served as the bane to development and the potential to impact the world positively. The expectation is that maintenance culture management will not only boost Nations' growth and development but also increase gross domestic product by attracting foreign direct investments. In this work, Africa's global impact could be measured by the extent of global demand for goods and services from Africa as well as the level of attractiveness of the general wellbeing of the citizens, physical facilities, environmental structures and operational processes that could woo investors to Africa.

\section{METHODOLOGY}

This exploratory paper took an introspective look at the macro, micro and mini level perspectives of Maintenance culture Management within the African continental environment through participative observation and desk research.

\section{CONCLUSION}

Africa can attain optimum level of growth and development and positively impact the global space. Maintenance culture management is top priority if there is a conscious desire for the attainment of efficiency and cost minimization as well as the need to save lives, finance and properties. However, if nothing is drastically and urgently done, the achievement of this feat could prove herculean and it will also be an exercise in futility to continue to invest in the attempt to better the lot of Africans and their potentials to impact positively on global development from the continent. A way forward may be to look into the underlying paradigm of this work which makes it imperative to ensure the enhancement of the maintenance culture consciousness of the key actors at the macro, micro and mini levels of our societies and check the potential hindrances to maintenance culture management. 


\section{REFERENCES}

African Development Bank.(2020).African Economic Outlook. https://www.afdb.org/en/knowledge/publications/ african-economic-outlook retrieved 21 February, 2020.

Amankwah, O., Wai, C. W., Mohammed, A. H.\& Baba, M.(2017). A review of sustainable maintenance management of public healthcare facilities in developing countries: The case of Ghana. International Journal of Real Estate Studies, 11(2),113-123.

Asimeng-Boahene L. (2017) Issues and prospects of African indigenous systems of governance: Relevance and implications for global understanding. In McKinley E., Smith L. (Eds.) Handbook of Indigenous Education. (pp.1-20). Singapore: Springer.

Bandara, A., Dehejia, R. \&Lavie-Rouse, S. (2017). Access to Household Resources and Human Development: Evidence from Survey Data for Tanzania. Journal of Human Development and Capabilities, 18, 399-423.

Beheshtifar, M. \& Safarian, M.(2013). HR maintenance: A vital factor to promote job commitment. International Journal of Academic Research in Business and Social Sciences, 3 (2),197-202.

File,W.T.(1993). Manufacturing engineer's reference book. Oxford: Butterworth-Heinemann.

Fonchingong, C.C. (2018). Optimising Community-Driven Development through Sage Tradition in Cameroon. Global Social Welfare, 5, 145-153.

Huitt, W. \& Dawson, C. (2018). Social development: Why it is important and how to impact it. In W. Huitt (Ed.), Becoming a Brilliant Star: Twelve core ideas supporting holistic education (pp. 123-146). La Vergne, TN: IngramSpark.

Jacobs, G. \& Asokan, N .(1999).Towards a Comprehensive Theory of Social Development. Human Choice, 152.

Juran, J. M. \& Godfrey, A,B.(1999). Juran's quality handbook. $5^{\text {th }} E d$. New York: McGraw-Hill.

Kangalawe, R. , Noe, C. , Tungaraza, F. , Naimani, G. \& Mlele, M. (2014).Understanding of Traditional Knowledge and Indigenous Institutions on Sustainable Land Management in Kilimanjaro Region, Tanzania. Open Journal of Soil Science, 4, 469-493.

Kisangani, E. F. (2009). Development of African Administration: Pre-Colonial Times and Since. Public Administration and Public Policy, 1, 1-7.

Mad Lazim, H. \& Ramayah, T. (2010). Maintenance strategy in Malaysian manufacturing companies: A Total Productive Maintenance (TPM) approach. Business Strategy Series, 11(6), 387-396.

Magutu, J. \& Kamweru, K.(2015). The phenomenon of building maintenance culture: Need for enabling systems. Global Journal of Engineering, Design \&Technology. 4(5),8-12.

Mungani, D.S. \&Visser, J.K. (2013). Maintenance approaches for different production methods. South African Journal of Industrial Engineering, 24(3),1-13.

Mwenzwa, E.M. \& Misati, J.A. (2014). Kenya's social development proposals and challenges: Review of Kenya vision 2030 first medium-term plan, 2008-2012. American International Journal of Contemporary Research, 4(1),246 -253.

Ojo,E.O. (2016). Underdevelopment in Africa: Theories and facts. Journal of Social ,Political and Economic Studies, 41(1), 89-103.

Patidar, L., Soni, V. \& Soni, P.(2017).Maintenance strategies and their combine impact on manufacturing performance. International Journal of Mechanical and Production Engineering Research and Development (IJMPERD), 7(1),13-22.

Poku,K. \&Lamptey,D. (2014). Maintenance culture and its effects on organizational productivity in small medium scale enterprises in Ghana. International Journal of Management and Human Resources. 2(1), 127-136.

Suwaibatul Islamiah A. S., Abdul Hakim M., Mohd S.M., \&Mariah A. (2012) Determinant Factors In Development Of Maintenance Culture In Managing Public Asset And Facilities. Procedia - Social and Behavioral Sciences, 65, $827-832$.

Tijani ,S. A., Adeyemi, A.O.\& Omotehinshe,O.J. (2016) Lack of Maintenance Culture in Nigeria: the bane of National Development. Civil and Environmental Research 8(8), 23-31.

Usman, N. D., Gambo, M. J. and Chen, J.A. (2012) Maintenance Culture and its impact on the construction of Residential buildings in Nigeria. Journal of Environmental Science and Resource Management, 4, 69-81.

Vygotsky, L. S. (1978). Mind and society. Cambridge, MA: MIT Press.

Worldometer(2020). World Population. https://www.worldometers.info/world-population/africa-population/ Retrieved 22 February, 2020. 